\title{
THE USE OF 3D MODELS IN INTEGRATED SURVEY: THE CHURCH OF ST. THOMAS OF VILLANOVA IN CASTEL GANDOLFO
}

\author{
M. Canciani ${ }^{\mathrm{a}}$, M. Saccone ${ }^{\mathrm{b}}$ \\ a Roma Tre University, Department of Planning and Architectural Studies, mcancian@uniroma3.it, \\ ${ }^{\mathrm{b}}$ sacc1@hotmail.com
}

KEY WORDS: San Tommaso da Villanova in Castel Gandolfo, G.L. Bernini, Integrated survey, Measurement model, Design model, Representation model

\begin{abstract}
:
The research illustrated below describes the integrated survey method as applied to the Church of St. Thomas of Villanova in Castel Gandolfo, the work of G. L. Bernini. In particular, integration of the various survey methods with 3D modelling to reconstruct all the elements with complex and/or hard to measure geometries has made it possible to obtain an accurate survey model. Comparison of this model with Bernini's original project, based on the analysis of several drawings, has given a clearer view of certain aspects of the design and of Bernini's planning methods.
\end{abstract}

\section{BERNINI IN CASTEL GANDOLFO}

This document illustrates a study focusing on the use of models for the survey, analysis and representation of architecture. The study was carried out by the Department of Planning and Architectural Studies at Roma Tre University in collaboration with the Vatican Heritage Superintendence.

The study in question regards the Church of St. Thomas of Villanova in Castel Gandolfo. Built between 1658 and 1662, the church was commissioned by Pope Alexander VII Chigi and designed by Gian Lorenzo Bernini.

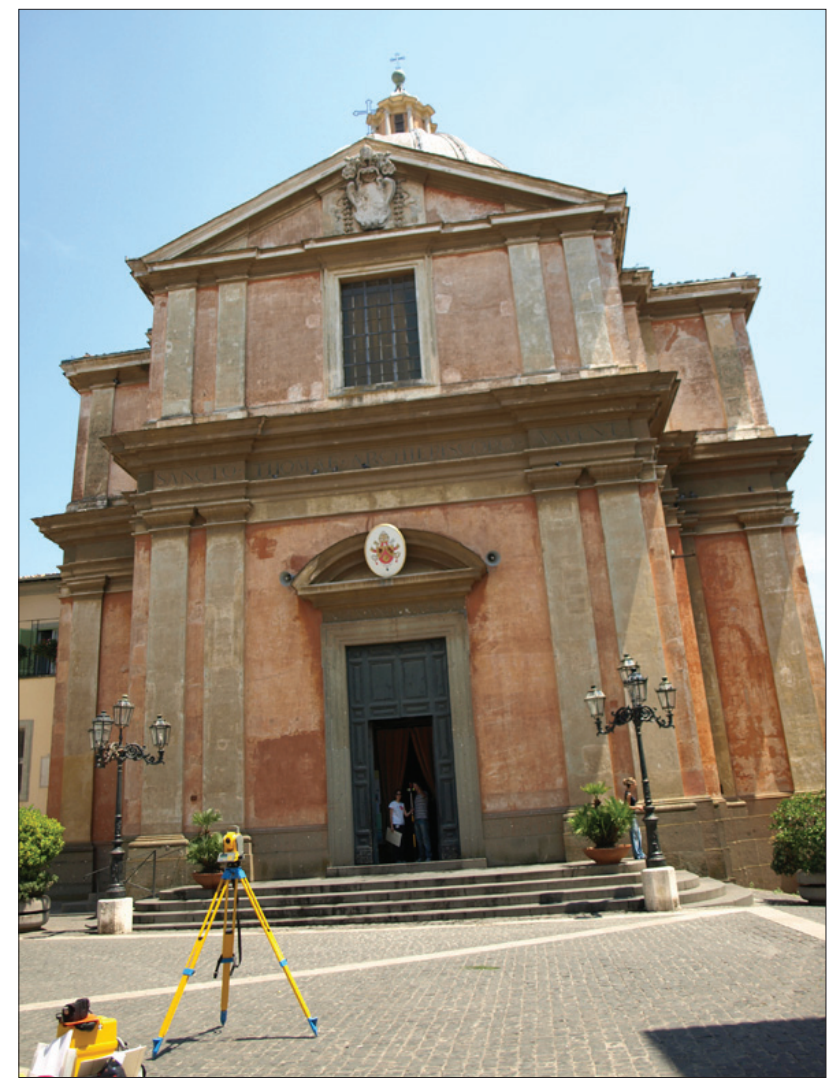

Figure 1. Photo of St. Thomas of Villanova in Castel Gandolfo
It is located on the east side of the square in Castel Gandolfo at the top of a hill that runs from the square down to a lakeshore terrace. The church has two superimposed parts: the upper church accessed through the main entrance in the square and dedicated to St. Thomas of Villanova, archbishop of Valencia, and the lower, lakeside church consecrated to St. Nicholas to whom the old oratory was dedicated.

The layout of the upper church is based on a Greek cross, with a tholobate carrying a dome with an acute angled outer profile; the main facade, the central body of which stands out into the square, has two superimposed orders of columns, top and bottom, with a proportion of two to one.

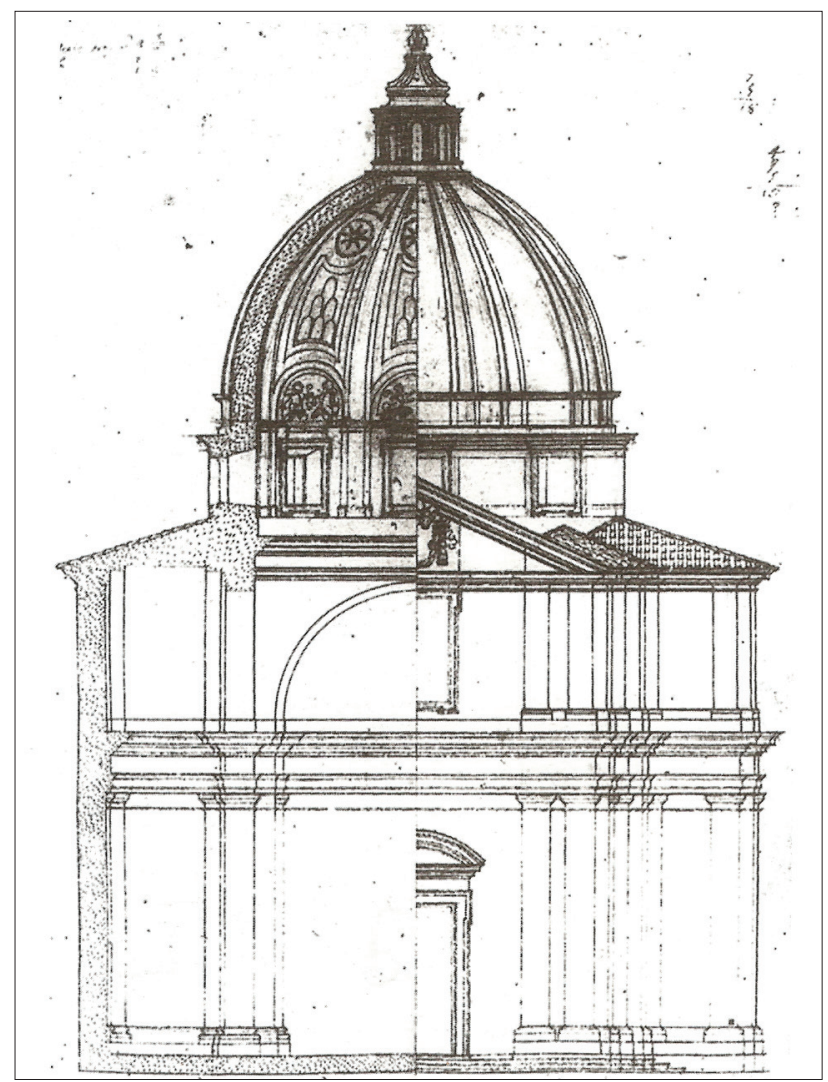

Figure 2. Bernini's design: Front view and cross section, 16581660, Biblioteca Vaticana, Chigi P VII 12 f. 11 


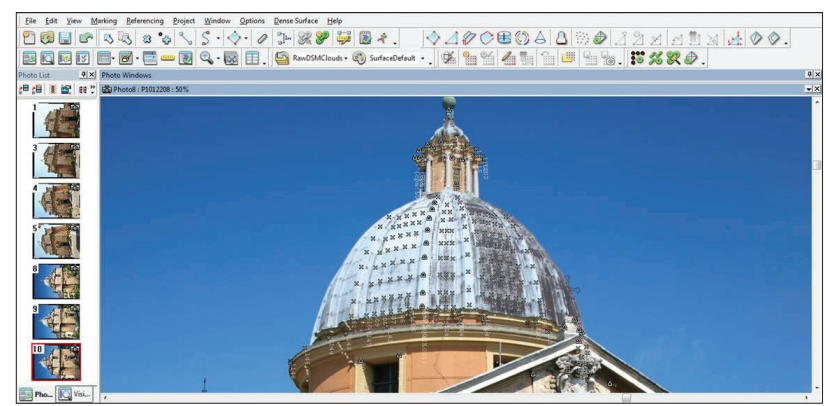

a)

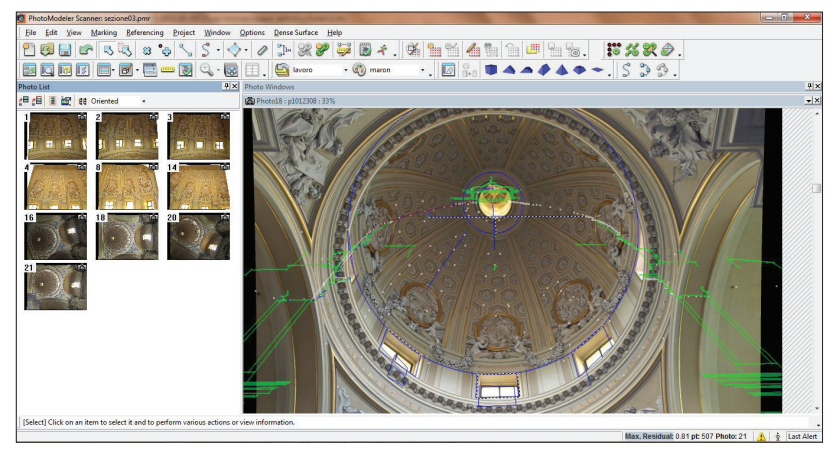

c)

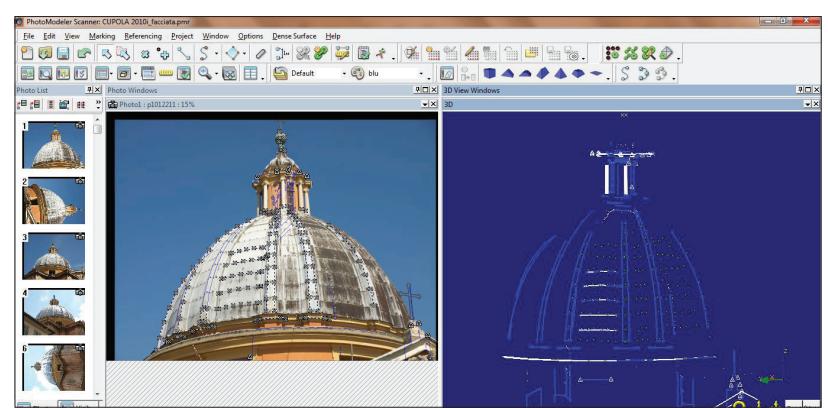

b)

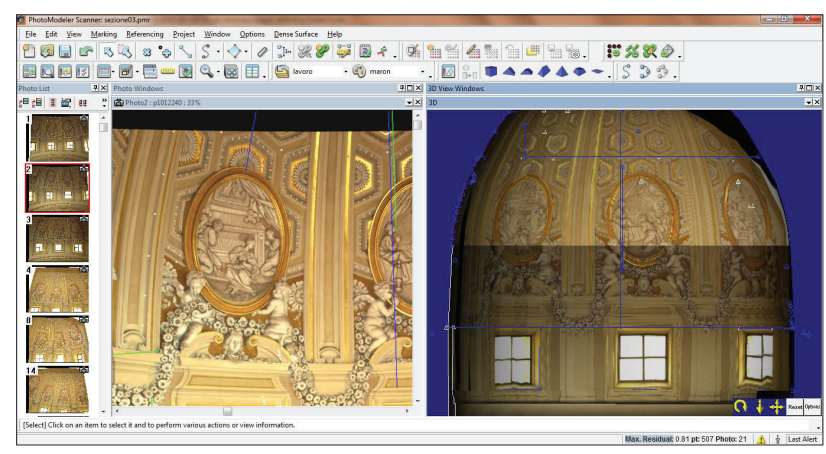

d)

Figure 3. Photomodeler screen shoot: a) topographic survey points marked on photo for photogrammetric restitution; b) restitution of the geometric model of cupola; c) theorical section model superimposed on photo; d) represented model of the intrados of the cupola

\section{THE DESIGN AND SURVEY DRAWINGS}

Except for Bernini's original design and survey drawings, very little else has been produced about the church in recent years. Bernini's designs for the church illustrate the changes he made to the original idea while construction was ongoing; drawn between 1658 and 1660, they are now housed in the Vatican Library.

A first series of drawings (the initial draft layout, the front view overlooking the square and a side view, the plan drawing) $*$, refers to a version of the design with a tiburio and with the church isolated from the general context of the square, two orders of columns of the same size on the facade, the tiburio surrounding the drum in the central area; a second series of drawings (the cross-section, the main profile, drawings for construction of the cupola, the clerestory and the bell tower, studies for the lower church)**, relate to a solution with an acute angled cupola, differently proportioned orders of columns in the facade, connection of the lower and upper church and addition of the sacristy. The survey documents and drawings by A. and G. Pierangeli were published in 2005 (Apa, Pierangeli, 2005); they include two floor plans, the elevations and transversal section of the church. Although the 1:100 scale drawings make it possible to assess the architecture designed by Bernini, it doesn't help to appreciate all the architectural details and sophisticated solutions he envisaged. Furthermore, some drawings are inconsistent with the actual architecture of the church, while others are oversimplified graphic representations.
As a result, the Vatican Heritage Superintendence commissioned a new 1:50 scale survey in order to obtain an extremely detailed graphic restitution of the church. The aim of the survey was to help in the study and enhancement of Bernini's original design and act as the basis for a detailed architectural restoration project.

\section{MEASUREMENT MODEL, SURVEY MODEL, DE- SIGN MODEL, REPRESENTATION MODEL}

To carry out an accurate and exact survey (for example in the case of the Church of St. Thomas) and produce illustrations showing the importance of detail in the overall design, we developed a combined method that included different kinds of direct survey procedures - traditional, topographic, photogrammetric. This was achieved by developing four georeferenced models; the measurement model, the survey model, the design model and the representation model.

The measurement model is a mix of more than one direct and indirect survey model coordinated in what is known as an "integrated survey" system in which each survey method is used according to its specific characteristics. Each model is closely linked to the others using a system of common points and georeferentiation in the same system of coordinates.

The survey model was used to reconstruct the drum, dome and lantern of the church and exploits "basic knowledge", in other words, formal models illustrated in studies on the history of architecture, treatises and historical, archival and documentary 


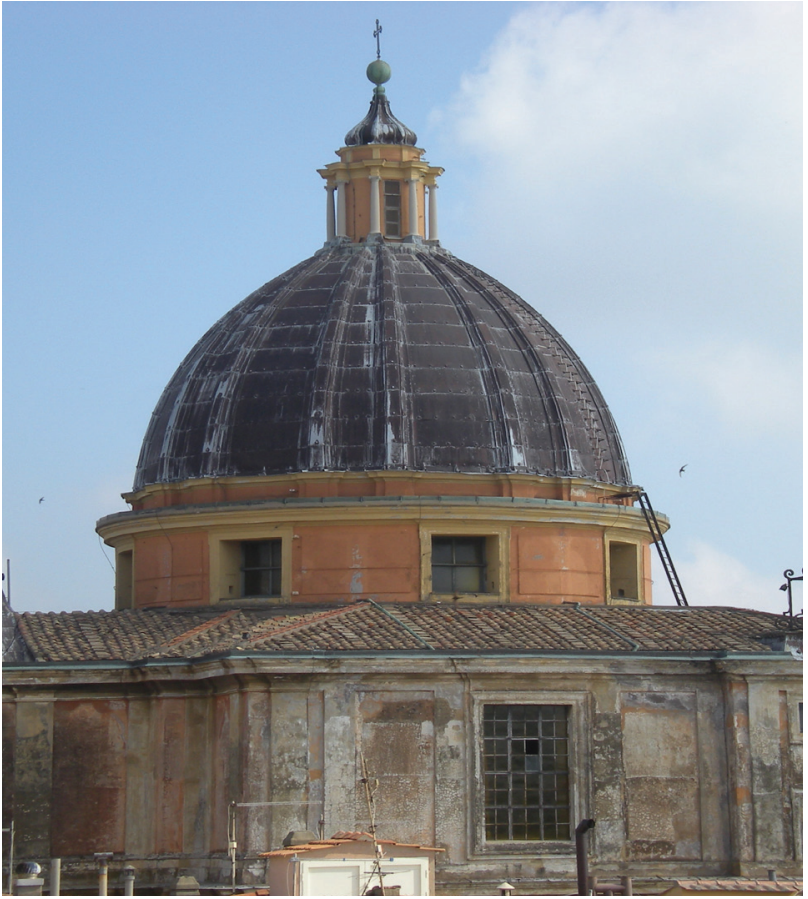

Figure 4. Photo of St. Thomas cupola

studies.

The design model was reconstructed analysing Bernini’s original drawings.

The representation model collates and summarises the data provided by the measurement and theoretical models; it selects the appropriate $3 \mathrm{D}$ data as well as the $2 \mathrm{D}$ images of plans, elevations and sections so that the drawings are correctly represented.

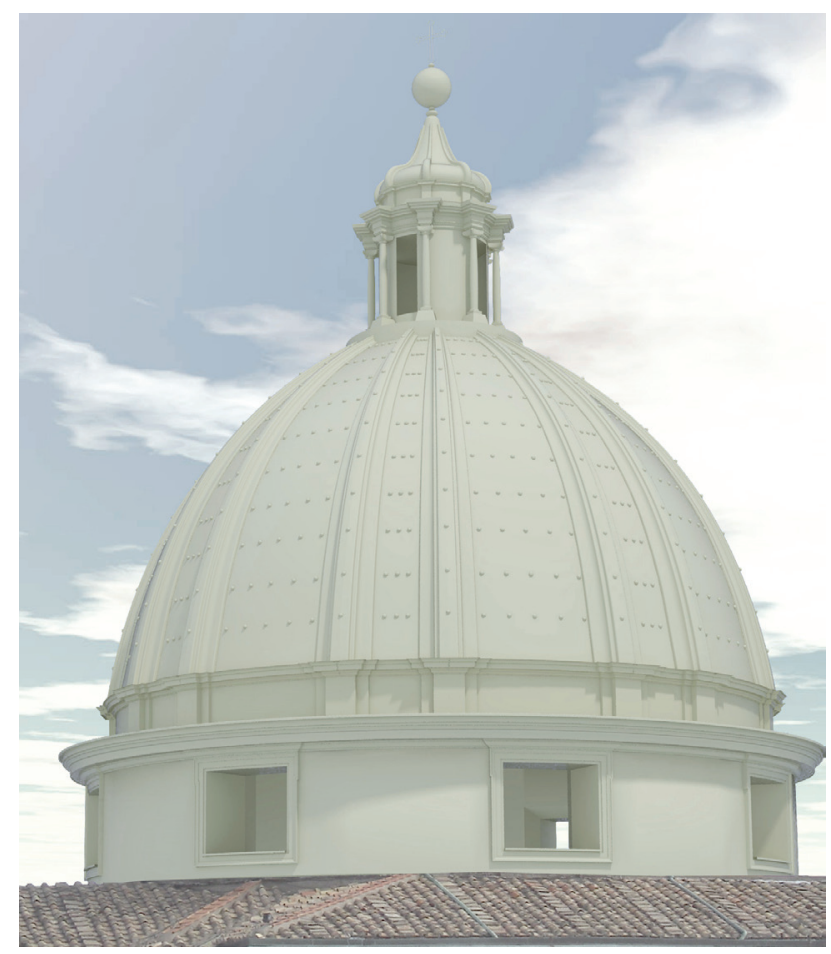

Figure 5. The survey model of the cupola

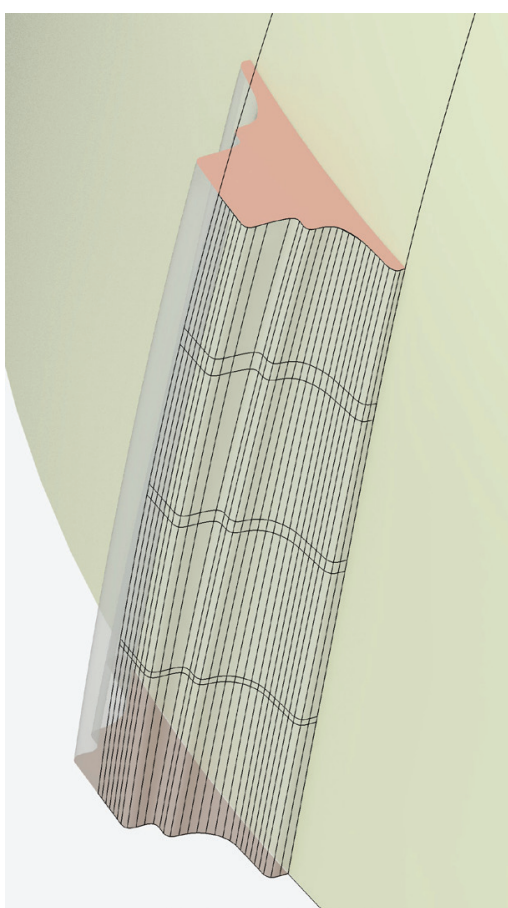

Figure 6. Groin costruction model of cupola. In evidence the isocurves that set the surface

\subsection{The measurement model}

The measurement model has been created applying the "Integrated Survey" method. This method uses various systems: of an instrumental, topographic, photogrammetric and traditional direct type, which are integrated thanks to a common georeferencing system.

The topographic survey, which uses a total station, generates a reference polygon with the topographic measurement stations at

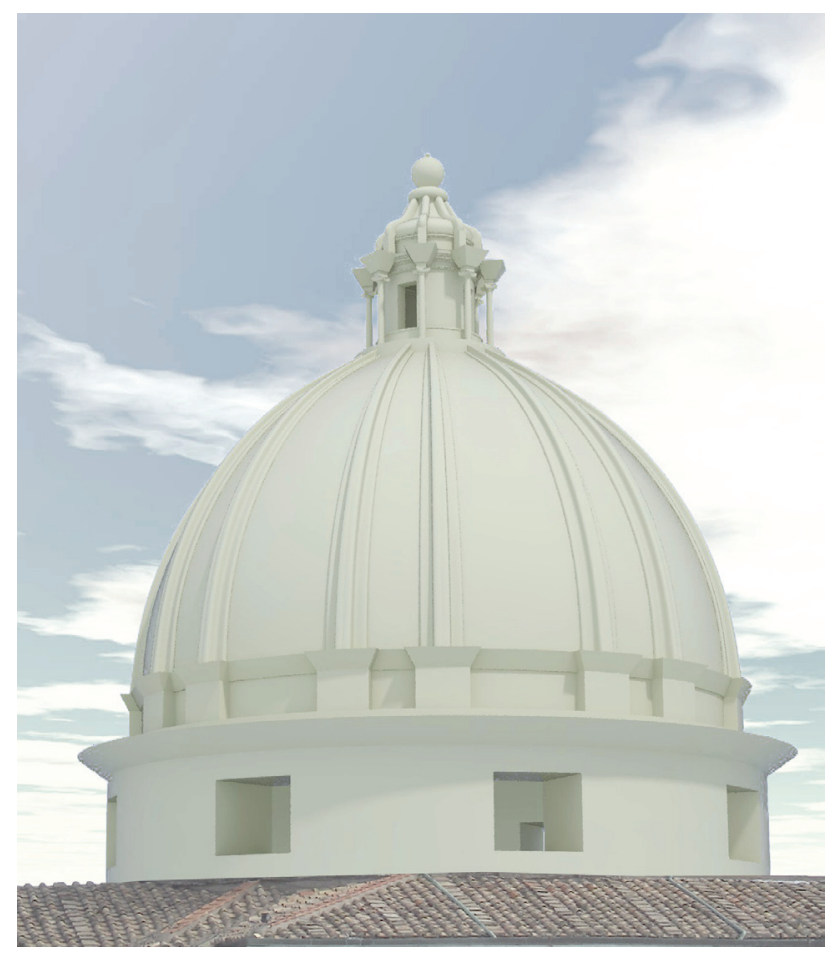

Figure 7. The design model of the cupola 
its vertexes, and this forms the basis for georeferencing of all the survey models obtained using the various methods. A survey of the object is then carried out, while at the same time the preparatory drawings are prepared and then a manual survey of all the details (moldings, decorations, etc. etc.). All the preparatory drawings are inserted in the general reference system (as they contain the "known points") and carry information on dimensions for control and verification purposes. The next phase is the photogrammetric survey. Using a reproduction software, it is possible to use the photographs to reconstruct a photogrammetric model in which pairs of photos taken using the orientation in the general reference system (by importing the "known points") make it possible to measure all the objects that are not detected using the other methods. The result of this process is a topographic and a photogrammetric model that form the basis upon which to create the design model.

\subsection{The survey model}

Right from the early stages of work a double problem was encountered. On the one hand there was a problem performing a proper survey on the roof and cupola of the church due to access or visibility questions, and on the other hand there was a problem representing the curvature of the cupola and groins properly. For this reason it was decided to create a complete three-dimensional model of the drum, the cupola and the entire decorative system in the clerestory. The model, which is constantly verified using the few points that can be surveyed, has been divided into four main

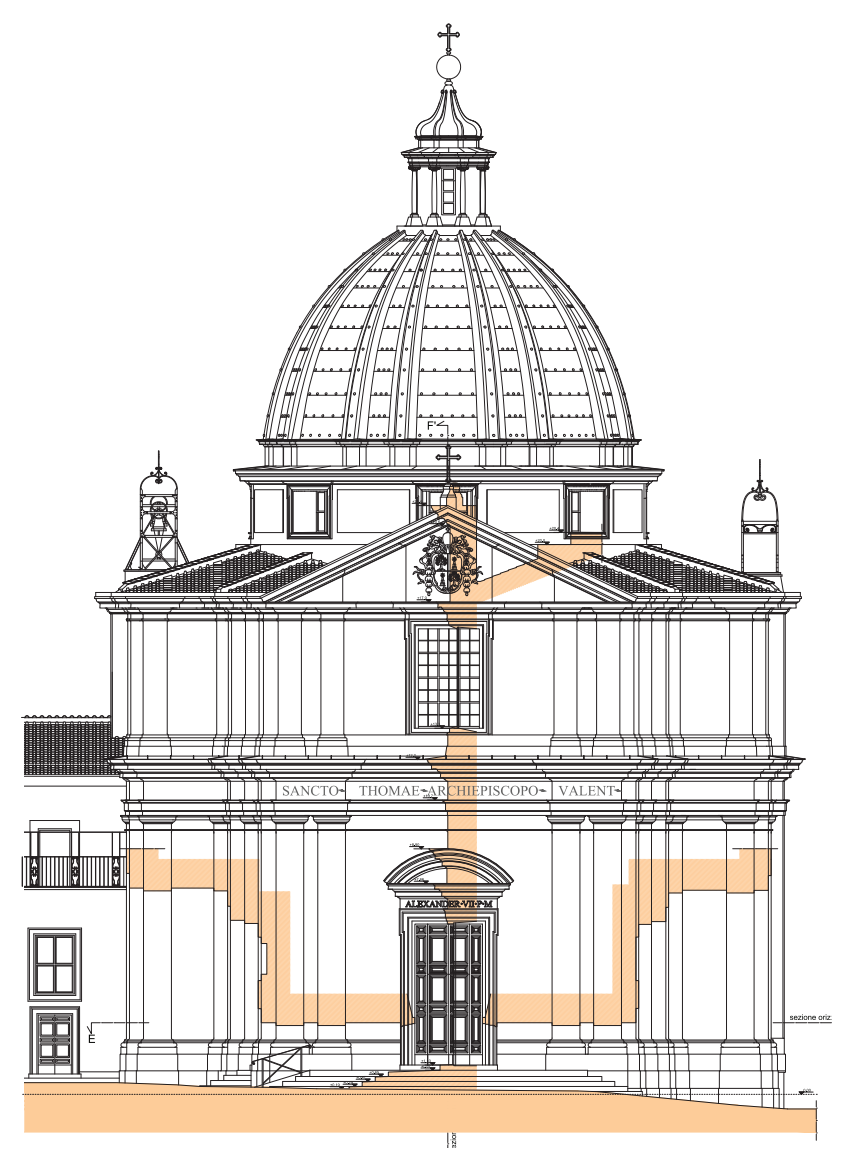

Figure 8. Represented model: Front view with in situ section parts: the drum, the cupola, the groins and the clerestory. The cupola has been constructed as surface of revolution, which by definition requires an axis of rotation and a generatrix curve. The axis has been identified starting from the horizontal section (plan) of the church, using the topographic survey model. Various circumferences have been built (on three points) passing through the centre of the four pilasters that support the drum, obtaining in this way a projection of the axis itself. Construction of the generatrix required use of the photogrammetric survey. Thanks to this instrument it was possible to draw all the elements with great precision, in particular the joints in the lead sheets that cover the outer surface of the cupola ad even the nails in the sheets themselves. In particular the drawing of the nails, which are almost perfectly aligned, allowed definition of the outer profile both of the cupola and of the groins. The drum has been modelled as a surface of revolution using a procedure similar to the one described for the cupola, with the difference that the generatrix was detected using the direct method thanks to the ability to access a walkway around the perimeter. The clerestory and groins, which cannot be accessed and are difficult to measure using the topographic instrument, were measured and recreated from the photogrammetric model. Construction of the groins in particular involved a special study relating to their geometry. The curvature of the outer profile is different from that of the inner profile, which rests on the crown of the cupola. Furthermore, the initial section and the final section of the groin are different not only in size and proportions, but also in geometry. As a result it was necessary to build a bicubic surface interpolated between four edge curves (Coons surface), dividing the groin in half as illustrated in fig. XX.

The clerestory and its decorative system has been modelled as a surface of revolution whose axis coincides with that of the cupola. The generatrix in this case derives from the topographic survey model and from the preparatory drawings made on site. The composite columns that support the groins rest against the central body of the clerestory. The position and dimensions of the nails on the lead sheets on the cupola have also been obtained from

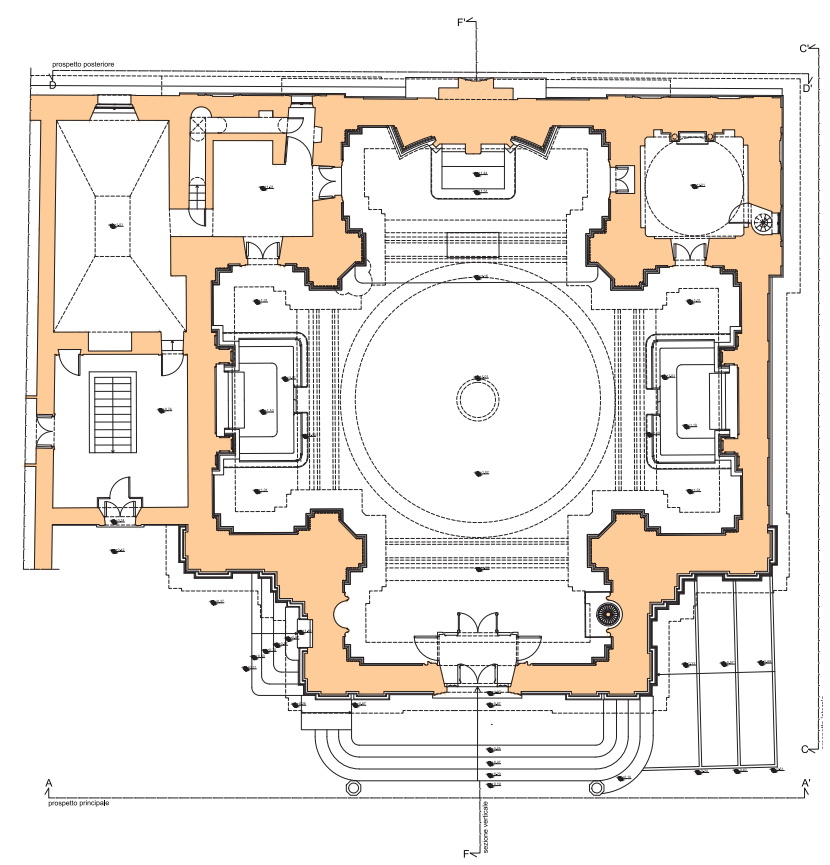

Figure 9. Represented model: plan view 


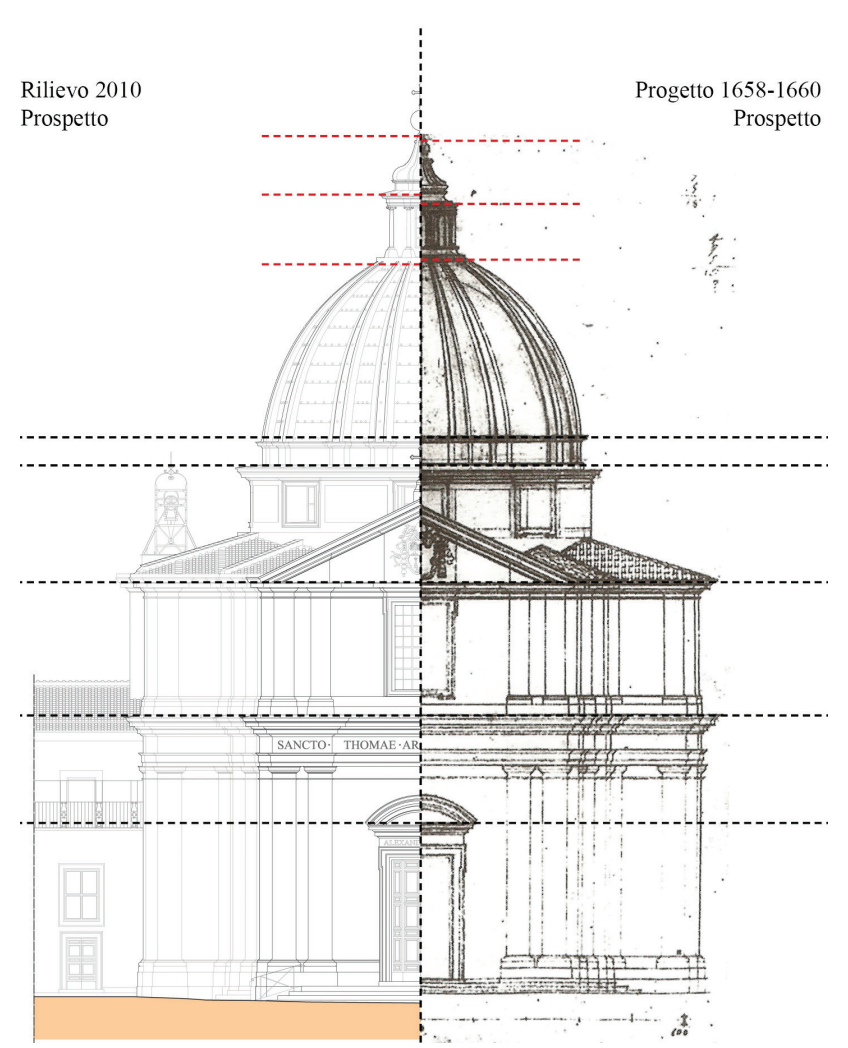

Figure 10. Comparison of front view: survey drawing (left) Bernini's design drawing (right)

the photogrammetric model and inserted in the design model to complete the work.

\subsection{The design model}

The design model derives from knowledge of the church's architecture as it was planned and designed by Gian Lorenzo Bernini. Starting from drawings from the period, which were digitalised and entered into the general reference system, a three dimensional model of the drum, the cupola with groins and the clerestory has been created. When constructing the cupola as a surface of revolution, the same axis used in the topographic survey model was used, while the generatrix was drawn (obtained or derived) from Bernini's section. Again in this case, construction of the groins was carried out using a Coons surface. The curvature of the outer profile is the one from Bernini's section, while that of the inner profile rests on the crown of the cupola. The sections, on the other hand, are similar to those in the survey model.

\subsection{The representation model}

As stated above, one of the main problems in representing the views of the Church of St. Thomas was drawing the curves of the groins. To solve this problem, 3D rendering of the orthogonal views was carried out. From the images obtained it was possible to draw all the elements in their correct forms and positions, particularly as regards the elements directly in view, such as groins, nails, etc. etc. The model shown summarises the information from the measurement and survey models, carrying out a selection of the 3D information in order to give a correct two-dimensional representation in the form of plans, views and sections. A plan view at a height of $2.60 \mathrm{mt}$, a longitudinal section and the three visible views (the fourth abouts onto another building) of

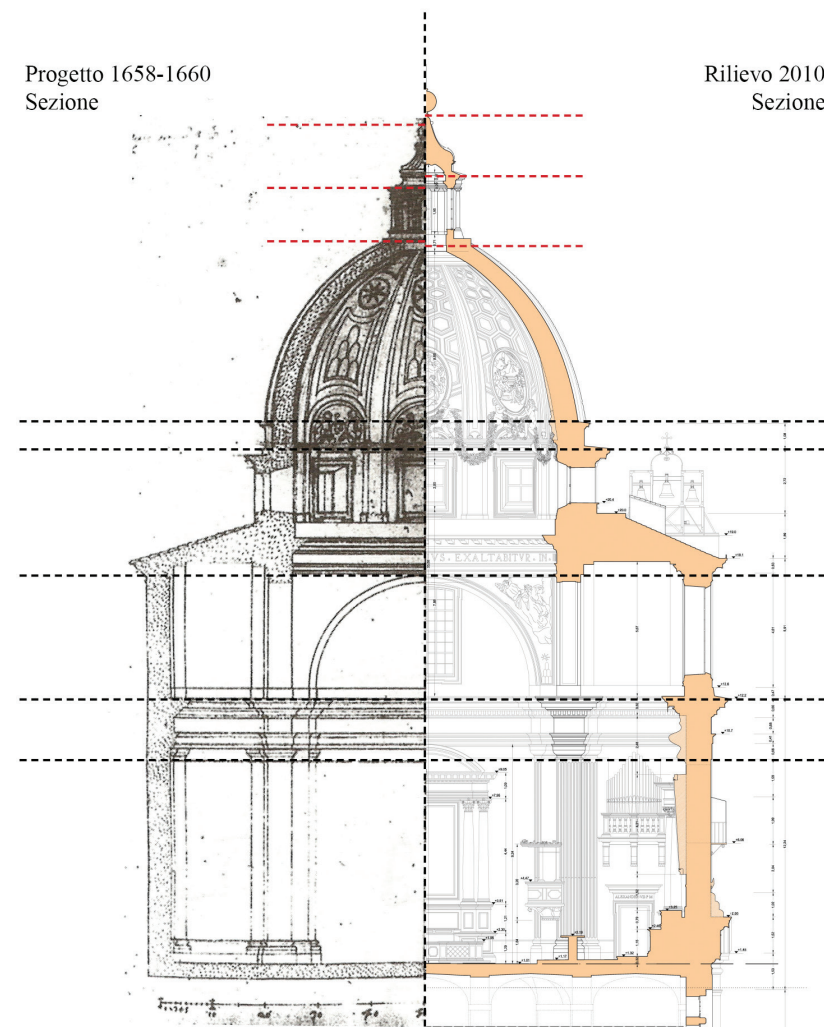

Figure 11. Comparison of section: Bernini's design drawing (left) - survey drawing (right)

the Church of St. Thomas were prepared. The drawings were all in a scale of 1:50, showing indications of dimensions, heights and "in situ" sections. The decision to provide "in situ" sections indicates a desire to highlight the third dimension even in the two-dimensional views.

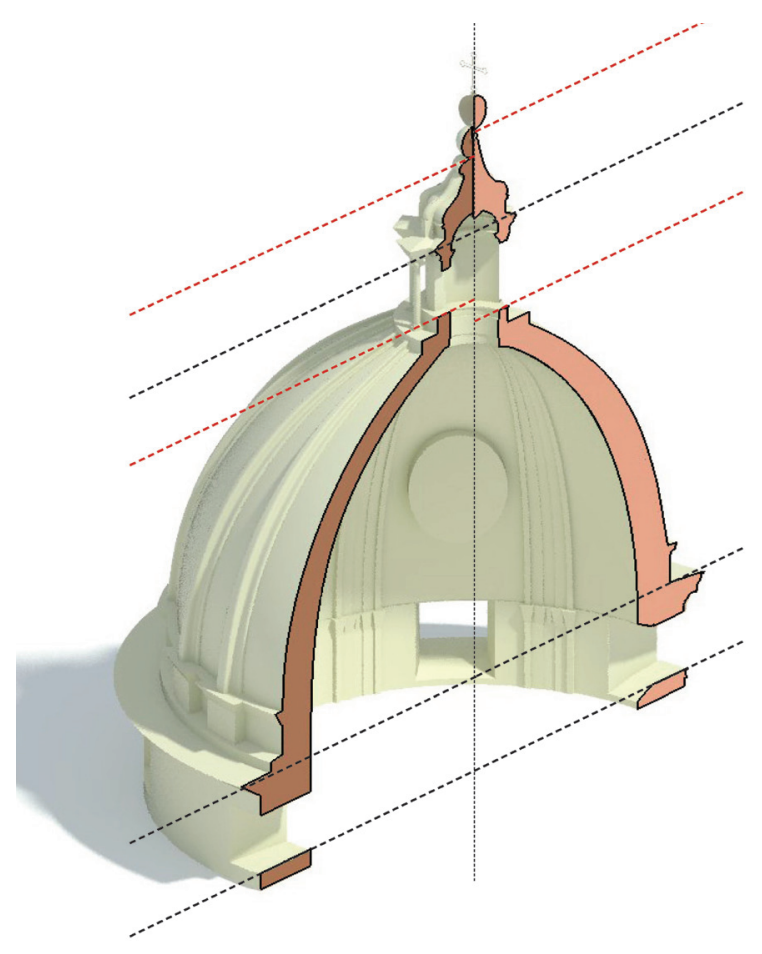

Figure 12. Comparison plan model (left) - survey model (right) 


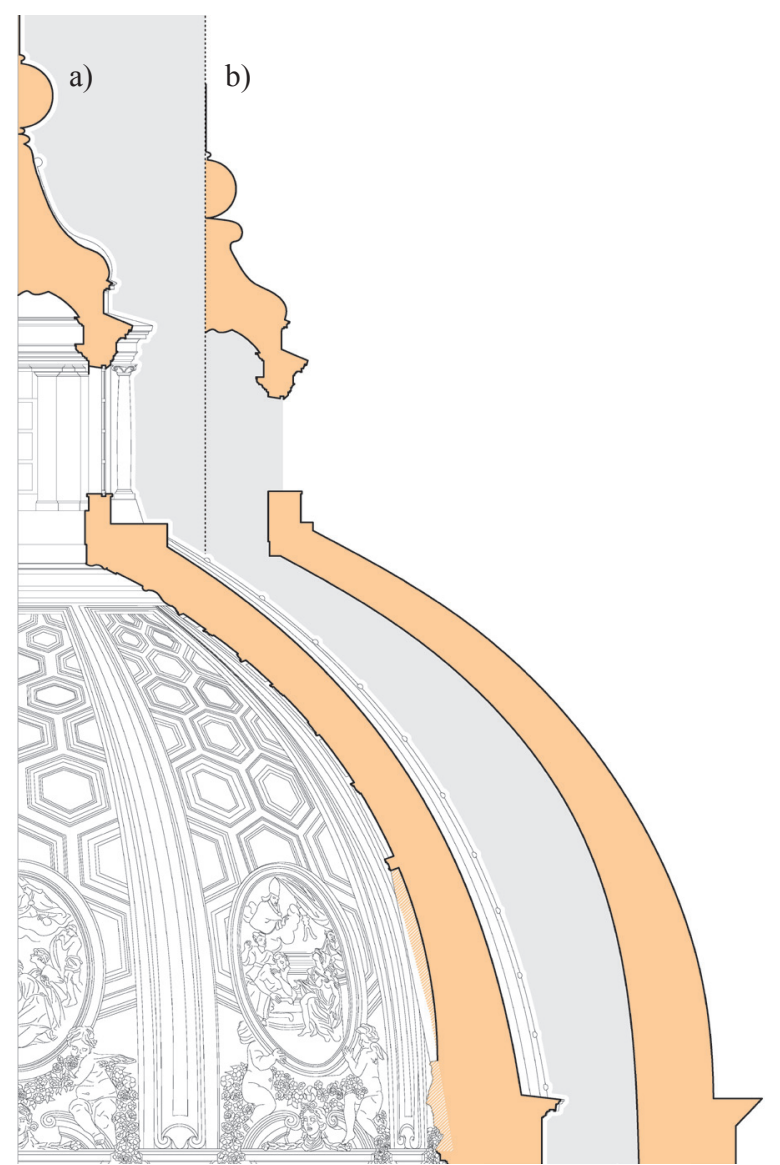

Figure 13. Comparison of detail section of cupola and lanterna: a) design model; b) survey model

\section{SUPERIMPOSING SURVEY / DESIGN}

Superimposing the survey drawings and the plan drawings highlighted an extraordinary correspondence between Bernini's original design intentions and the actual structure of the church, together with a high level of congruence and precision in the plan drawings. Analysis was carried out in particular on drawing located in Biblioteca Vaticana (Chigi P VII 12 f. 11), using the right hand portion, which shows a half-view of the main facade, abutting onto the left hand portion of the survey view and the left hand portion, relating to the cross section of the church, abutting onto the right hand section, relating to the survey.

As regards comparison of the views, there is a substantial correspondence of positions, both as regards the height measurements, those of the main facade and the drum, the eaves, the cupola springer, the clerestory, and as regards the dimensions and proportions of the elements in the architectural order, the base plinth, the main door, the entablature frieze; also not the correct and strict representation of the roof covering layers, orientation of the windows in the drum, the design of the cupola groins; drawing of the corner solution of the architectural order, which is simplified at the corner, rectifying the curved moldings. This solution is a detail that highlights the Bernini's skill in solving the problem of turning back the order and demonstrates how this was done exactly as shown in the plan drawings.

When comparing the sections, as in the case of the view, the correspondence and congruence between plan and execution can be noted, up to the level of the drum (for example the windows and the cornice connecting with the cupola), whereas the section of the cupola is slightly different. In Bernini's plan the cupola was taller and thinner, with a more steeply inclined curve to the section, whereas in the actual construction the cupola is fatter, with the central aperture, on which the clerestory rests, is at a lower height and the clerestory itself is reduced in height. The inner profile of the cupola is also substantially different: in the one actually constructed there are a series of boxes encased within the pilaster strips, with the windows surmounted by cherubs and garlands and large ovals with figures in bas relief, whereas in the drawings the structure was lightened by a series of arches, placed over the windows.

When observing Bernini's drawing, with the section next to the survey, another detail can also be seen, and is noted in particular in the survey section drawing, that is to say the church's internal and external molding is more or less aligned horizontally, and in the plan drawing the internal and external part of the molding actually coincides.

The two sets of molding, which Bernini intended to stress the visual and spatial continuity between the exterior and the interior of the church, differ only in that the internal one is more curving (some of the strips in the external molding are replaced by grooves in the internal molding), while the external one is more regular.

\section{CONCLUSIONS}

One aim of this study is to emphasise the importance of an integrated survey method in the organisation and correct management of the data provided by each survey. Another is to fully exploit the potential afforded by the analysis and comparison of the different models. In fact, the study's added value lies in the elaboration of a method allowing consultation of the survey model during the entire process and the superimposition of the

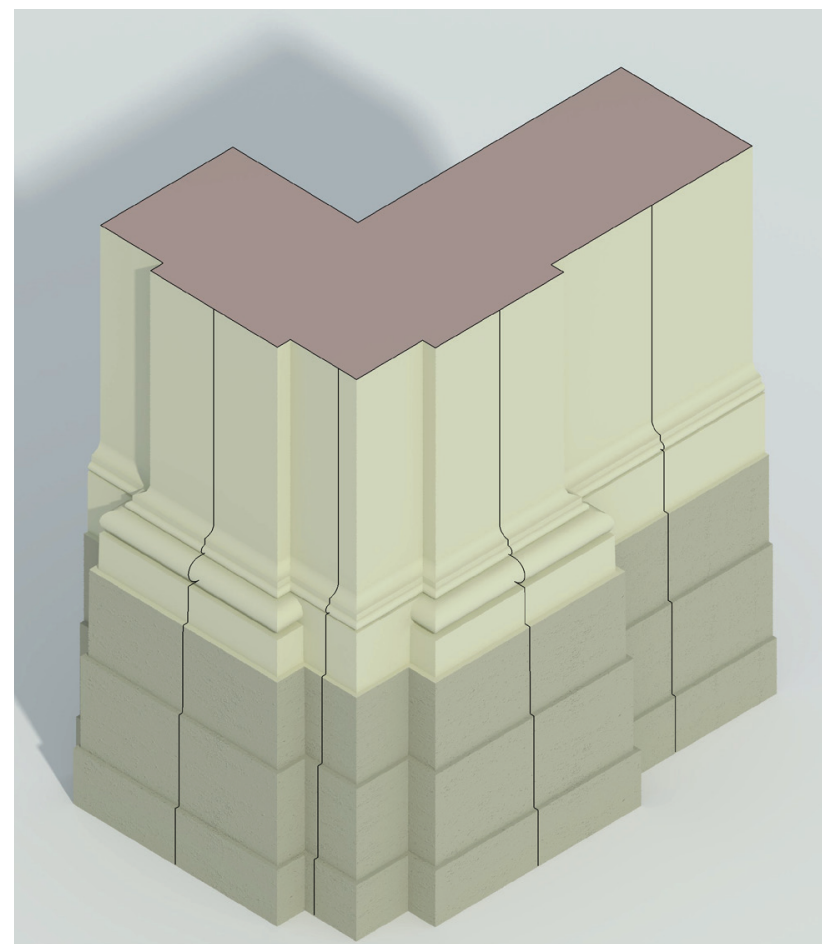

Figure 14. Axonometric view of the Church angle solution with in situ sections 
measurement and theoretical model in order to underscore differences, deficiencies and anomalies between the original design, shown in its "ideal configuration", and the actual building, as shown by the detailed survey.

When comparing the survey models and the plans, not only the accuracy and precision with which the drawings were made can be seen, but also the strict method employed by Bernini when developing the plan, using compound drawings, combining the section with the prospect view, to underline the correspondences and alignments between interior and exterior and to establish the reference elevations.

\section{REFERENCES}

Apa M., Pierangeli A., 2005, Gian Lorenzo Bernini La Chiesa di San Tommaso da Villanova a Castel Gandolfo, L'Aquila Maestri D., Canciani M., Spadafora G., 2001. Archaeological Survey: data processing experimentation and direct observation, in The Cipa International Archives of Cultural Documentation, Volume XVIII, Berlin.

Maestri D., Docci M., 1999. Manuale di rilevamento architettonico. Editori Laterza, Bari 1993, reprint 1999.

Maestri D., Canciani M., Spadafora G., 2007, The integrated survey for the knowledge and the documentation of the archaeological heritage: the "Villa dei Misteri in Pompei.", in the archives of XXI CIPA international simposium "Anticipating the future of the cultural past", Atene.

Canciani M., 2007, Il sistema informativo geografico come strumento progettuale: il caso di studio del Masterplan della Medina di Costantina", in the archives of EARCOMM 2007 "Sistemi informativi per l'architettura", Ancona.

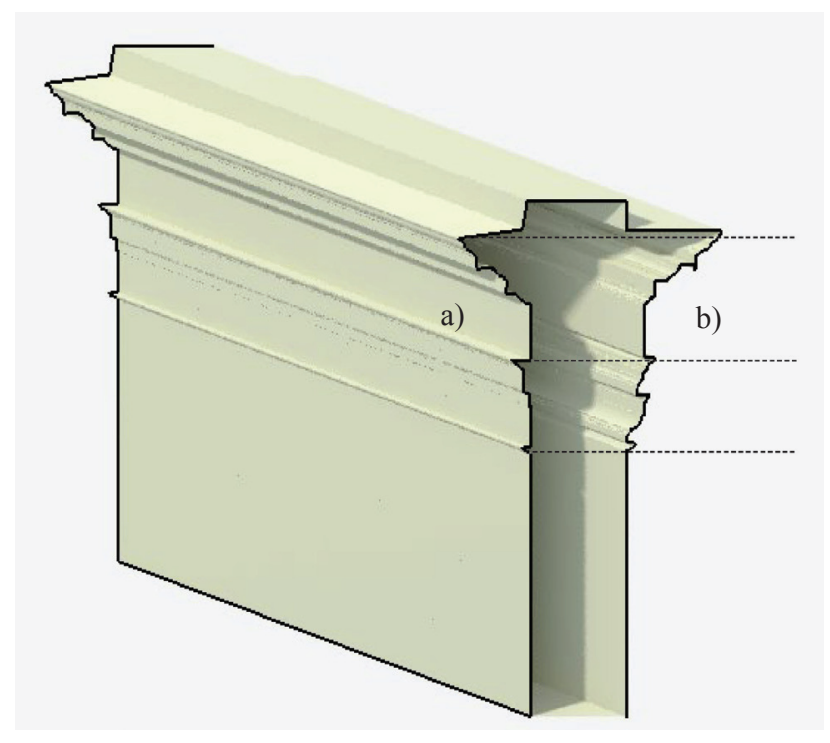

Figure 15. Detail of the mouldings at a) exterior end b) interior façade 